\title{
Examining Student Learning Outcomes and Engagement in Engineering Entrepreneurship Education Programs
}

\author{
Prateek Shekhar ${ }^{1}$, Aileen-Huang Saad ${ }^{1}$, and Julie Libarkin ${ }^{2}$ \\ ${ }^{1}$ Department of Biomedical Engineering, University of Michigan, Ann Arbor, MI, USA \\ ${ }^{2}$ Department of Geological Sciences, Michigan State University, East Lansing, MI, USA \\ Corresponding Author: aileenhs@umich.edu
}

\section{BACKGROUND}

The professional context for the future engineer is changing. Engineering graduates can no longer expect a career with a single employer and they must be prepared to meet the needs of diverse organizations. Companies are looking for engineers who can identify unmet needs, problem solve under time constraints, and adapt to technological change. In response to changing career needs, higher education institutions are reforming how they train engineers. Most recently, this reform has led to the incorporation of entrepreneurship into engineering undergraduate curriculum. As more programs rush to launch engineering entrepreneurship programs, it is critical that we better understand the outcomes of entrepreneurship education and how programs engage diverse student populations. In our poster, we present our two projects assessing learning outcomes of engineering entrepreneurship programs and examining student participation.

\section{PROJECT GOALS}

Project 1: Developing assessment material that can be used by engineering faculty, staff and administrators launching engineering entrepreneurship programs. We are assessing three student outcomes:

- Entrepreneurial Self-Efficacy

- Entrepreneurial Behaviour

- Entrepreneurial Knowledge

Project 2: Understanding engineering students' engagement in entrepreneurship programs by:

- Developing a conceptual model for understanding students' participation in entrepreneurship programs

- Examining differences across student gender

- Examining alumni responses to understand engagement, motivation, perceived barriers and challenges.

\section{EMERGENT FINDINGS}

Entrepreneurial Self-Efficacy (ESE) Assessment: Validated McGee's ESE measure was used to assess self-efficacy changes with respect to: Searching, Planning, Marshaling, Implementing Finance \& Implementing People. Students' ESE pertaining to searching, marshaling, and implementing-finance were significantly higher at the end of entrepreneurship courses when compared to beginning of course responses.

Entrepreneurial Knowledge (EK) Assessment: We examine EK by assessing their understanding of customer discovery process. The five open-ended questions assessed the three customer discovery steps: feedback, iteration and pivot. Diverse student postsurvey responses indicate that they were able to understand and internalize the taught concepts.

Entrepreneurial Behavior (EB) Assessment: Using literature review and expert feedback we have identified and defined key constituents of EB. Also, we have developed a 30-item instrument to assess EB constructs: opportunism, networking, risk management, adaptability and perseverance. Our ongoing work tests the survey for internal consistency and will assess changes in students' EB after engaging in entrepreneurship programs.

Understanding Student Participation: Based on a systematic literature review of entrepreneurship education assessment literature, we have developed a conceptual framework for studying student Participation in Entrepreneurship Education Programs (PEEP). This model synthesized student participation and entrepreneurship education theories. Guided by adult learning and incorporating entrepreneurship relevant theories, the model conceptualizes participation in EP as outcomes regulated by multiple variables. 


\section{CONCLUSION}

As the rate of technology change continues to increase and the nation's economic future becomes increasingly dependent on innovation, engineering schools must adapt to the needs of the new economy. By understanding how students learn to be entrepreneurially minded, we can affect how we are training future engineers. Concurrently, it is important to examine how these programs attract diverse audiences to ensure a diverse cohort of entrepreneurial graduates. The results of this work will offer faculty and administration a better understanding of how to create inclusive, evidence-based entrepreneurship education programs that can be assessed and integrated into engineering curriculum at scale.

\section{RECENT PUBLICATIONS}

[1] Shekhar, P., et al. Understanding Student Participation in Entrepreneurship Education Programs: A Critical Review. International Journal of Engineering Education, 34(3), 1060 - 1072, 2018.

[2] Huang-Saad, A.,Y., et al. Entrepreneurship in Higher Education: A Research Review for Engineering Education Researchers, Journal of Engineering Education, [Accepted]

[3] Morton, C.S., et a., Entrepreneurship education for women in engineering: A systemic review of entrepreneurship assessment literature with a focus on gender. Journal of Engineering Entrepreneurship, 8(1), 17-31, Winter 2017

[4] Hirshfield, L., et al.., Mapping engineering outcomes to the Lean Launch curriculum in the context of design. ASEE 124th Annual Conference, Columbus, OH, 2017

[5] Shekhar, P., et al., Cummings, R., Tafurt, Assessment of Student Learning in an Entrepreneurship Practicum Course. ASEE 124th Annual Conference, Columbus, OH, 2017.

[6] Huang-Saad, A. and Celis, S., How Student Characteristics Shape Engineering Pathways to Entrepreneurship Education. International Journal of Engineering Education, 33(2), 527-537, 2017.

[7] Aileen Huang-Saad, et al., "Unpacking the impact of engineering entrepreneurship education that leverages the Lean LaunchPad Curriculum", 2016 IEEE Frontiers in Education Conference (FIE) 